Research Article

\title{
Study on the "Pressure Relief and Yielding Support" Joint Prevention and Control Technology for the Weak Impact Roadway in the Extremely Thick Coal Seam
}

\author{
Zengde Yin $\mathbb{D}^{1},{ }^{1,2}$ Jinxiao Liu $\mathbb{D}^{2,3}$ Wenbin Sun $\mathbb{D}^{2,3}$ Kebao Guo $\mathbb{D}^{4},{ }^{4}$ and Feng Zhang $\mathbb{D}^{3}$ \\ ${ }^{1}$ College of Safety and Environment Engineering, Shandong University of Science and Technology, 579 Qianwangang Rd, \\ Huangdao District, Qingdao 266590, China \\ ${ }^{2}$ Mine Disaster Prevention and Control-Ministry of State Key Laboratory Breeding Base, \\ Shandong University of Science and Technology, 579 Qianwangang Rd, Huangdao District, Qingdao 266590, China \\ ${ }^{3}$ College of Energy and Mining Engineering, Shandong University of Science and Technology, 579 Qianwangang Rd, \\ Huangdao District, Qingdao 266590, China \\ ${ }^{4}$ Shandong EIDO New Materials Co., Ltd., 28 Zhengyangmen St, Daiyue District, Taian 27100, China
}

Correspondence should be addressed to Jinxiao Liu; skd993938@sdust.edu.cn and Feng Zhang; zhangfeng08838@163.com

Received 3 December 2020; Revised 15 December 2020; Accepted 22 February 2021; Published 11 March 2021

Academic Editor: Hualei Zhang

Copyright $(2021$ Zengde Yin et al. This is an open access article distributed under the Creative Commons Attribution License, which permits unrestricted use, distribution, and reproduction in any medium, provided the original work is properly cited.

Weak impact occurs during roadway excavation in some extremely thick coal seams in China. Although this hazard is not enough to destroy the roadway, it will cause fracturing and large deformation of the roadway surrounding rock, resulting in the fracturing of bolts and anchor cables and bringing great difficulties to roadway support. In the hope of solving this problem, firstly, the reason for impact occurrence in the roadway of the extremely thick coal seam is analyzed from the perspective of energy. Then, the surrounding rock fracture evolution in such a roadway is explored by means of numerical simulation, microseism, and borehole observation. Furthermore, the "pressure relief and yielding support" joint prevention and control technology is proposed and applied to Yili No. 1 Coal Mine. The field engineering application results show that the joint prevention and control technology can effectively reduce the impact energy and ensure the stability of the roadway surrounding rock in the extremely thick coal seam. The research findings can provide a theoretical foundation for the roadway support of the same type.

\section{Introduction}

Coal is the dominant energy in China. In recent years, extremely thick coal seams in mining areas, such as Urumqi, Liuhuanggou, and Yili in Xinjiang, Huating in Gansu, Binchang in Shaanxi, and Yima in Henan, in western China suffer rock burst phenomena [1-4]. Multiple rock burst accidents have occurred in the driving faces $(120-600 \mathrm{~m}$ deep) of over 10 extremely thick coal seams (8-50 m thick).

Rock burst has become one of the main dynamic disasters threatening pit mining. Since the 1960s, the scholars all over the world have paid considerable attention to it and started to research on its generation mechanism. Concerning this disaster, Cook, Obert, Bieniawski, Qi, Dou, and other scholars successively put forward a variety of theories, including the strength theory, the rigidity theory, the energy theory, the three-factor theory, and the intensity weakening theory $[5,6]$. These research results play an important role in guiding safe mining.

At present, the rock burst prevention and control measures [7-17] at home and abroad, which can be classified into two categories, namely, regional prevention measures and local risk relief measures, mainly include blasting destressing, stress relief slot destressing, and borehole destressing. Reasonable application of these measures can effectively decrease the impact magnitude and the number of rock burst disasters. Cai et al. [18] proposed to prevent rock burst by means of blasting destressing. Through physical simulation, Lin and Zhou [19] analyzed the stress distribution around the coal body after the excavation of a stress 
relief slot in the coal roadway and discussed the coal outburst prevention mechanism of the slot. Through numerical simulation, Zhu et al. [20] studied the destressing effects at different slot depths under different ground stress conditions and revealed the mechanical mechanism of slot destressing operation in the surrounding rock. Jia et al. [21] investigated the destressing effect of the large-diameter borehole by means of laboratory test and numerical simulation. Zhu et al. [22] derived the method of quantitatively calculating the parameters of burst prevention boreholes based on the energy dissipation index and put forward the "zoning and classification" prevention and control concept for the area with impact danger in the working face. In addition, Qi et al. [23] and $\mathrm{Li}$ et al. [24] probed into the size effect and time effect of the destressing borehole, respectively. The above research studies provide theoretical guidance for the destressing of roadways prone to rock burst disasters.

The stability control of the roadway surrounding rock under the burst load has always been a research hotspot in the geotechnical engineering field at home and abroad. Under the burst load, roadway surrounding rock deforms seriously and quickly, which requires the supporting structure to have the properties of large deformation and yielding support. Considering this requirement, foreign experts developed and designed energy-absorbing bolts such as the cone bolt, the Roofex bolt, the Garford bolt, and the D-bolt [25-30], and Chinese scholars also conducted relevant research studies. Lian and Wang [31] designed a new type of prestressed yielding bolt by adding a yielding tube in the ordinary bolt. Zhang et al. [32] designed a yielding bolt with constant resistance by the extrusion and slip effect. The research team of $\mathrm{He}$ et al. developed constant-resistance and large-deformation bolts and anchor cables [33-39]. The development of these large-deformation bolts and anchor cables provides a new technology for roadway burst prevention support affected by dynamic pressure.

In some extremely thick coal seams, the impact energy of the driving face and its near-field area is relatively small (smaller than $10^{4} \mathrm{~J}$ ), which belongs to weak impact. When this kind of impact occurs, a vibration effect will be generated [40-42], inducing roadway surrounding rock vibration accompanied by a loud noise. For example, some mines in Yili mining area suffered this kind of weak impact during roadway excavation. Although such impact is not enough to destroy the roadway, it will lead to the fracturing and large deformation of the roadway surrounding rock and breakage of bolts and anchor cables, bringing great difficulties to roadway support. Currently, there is a lack of research on the roadway support affected by weak impact in extremely thick coal seams. In this study, the "pressure relief and yielding support" joint prevention and control technology is put forward based on the analysis of the mechanism of roadway impact in the extremely thick coal seam.

\section{General Situation of the Yili No. 1 Coal Mine}

Yili No. 1 Coal Mine is located in the Kazak Autonomous Prefecture of Yili in Xinjiang Uygur Autonomous Region, China. The mine, which has rich reserves, simple geological structure, and a designed production capacity of $10.00 \mathrm{Mt} / \mathrm{a}$, is developed through inclined shafts. The wellhead elevation is $+1,260 \mathrm{~m}$, and the shaft station elevation is $+1,060 \mathrm{~m}$. The belt transportation rise, the car rise, and the air return rise start from the shaft station and extend downward along No. 3 coal seam. No. 3 and No. 5 coal seams are the main mining coal seams. Located in the upper part of the Xishanyao Formation, No. 3 coal seam belongs to an extremely thick coal seam (average thickness: $12.35 \mathrm{~m}$ ) with low strength and poor crushing resistance. Its roof and floor are mainly composed of mudstone, siltstone, and fine sandstone which are all weak cemented soft rocks with low strength. Besides, they weather easily and contain a certain amount of water. Therefore, the three rises where thick top coal and bottom coal are reserved are arranged in the middle and lower part of No. 3 coal seam. The roadway layout is shown in Figure 1.

Entering No. 3 coal seam from the three rises, weak impact appears in the process of roadway excavation. With the increase in the mining depth, the energy of weak impact gradually increases. Its manifestation (below $6^{\#}$ crossheading) has the following four characteristics: first, under the dual effects of concentrated stress of the surrounding rock and weak impact, the roadway surrounding rock undergoes plate fracture and heaving sides. Part of the roadway sides becomes crisp and forms a cavity; second, weak impact mainly occurs in the driving, supporting, and coal transportation processes; third, the self-stabilization time of the surrounding rock is very short, and the weighting is quick; fourth, weak impact leads to serious deformation of the roadway surrounding rock and fracturing of bolts and anchor cables.

According to the result of ground stress measurement at the shaft station, the maximum horizontal principal stress is $151.3 \%-162.1 \%$ of the vertical stress and $125.5 \%-149.8 \%$ of the minimum horizontal principal stress. According to the impact tendency determination result, No. 3 coal seam possesses weak burst proneness, while its roof belongs to nonburst strata. The ground stress characteristics and the burst tendency of No. 3 coal seam are the preconditions for the weak impact of the roadway in the extremely thick coal seam of Yili No. 1 Coal Mine.

2.1. Analysis on the Near-Field Energy Evolution of the Surrounding Rock. In order to facilitate the analysis, the roadway is simplified into a circle. The roadway surrounding rock is an elastic energy storage area composed of coal and rock (Figure 2). The radius of the roadway is $r$, and that of the high-energy storage area of the roadway surrounding rock is $R$. The elastic energy accumulated in the unit length of the roadway surrounding rock can be expressed by the following equation:

$$
E=S_{r} \cdot \omega_{r}+S_{c} \cdot \omega_{c},
$$

where $E$ is the elastic energy accumulated in the surrounding rock in the high-energy storage area $(\mathrm{J} / \mathrm{m}) ; S_{r}$ is the area of rock stratum in the high-energy storage area $\left(\mathrm{m}^{2}\right) ; \omega_{r}$ is the energy density of rock stratum in the high-energy storage area $\left(\mathrm{J} / \mathrm{m}^{3}\right) ; S_{c}$ is the area of coal seam in the high-energy 


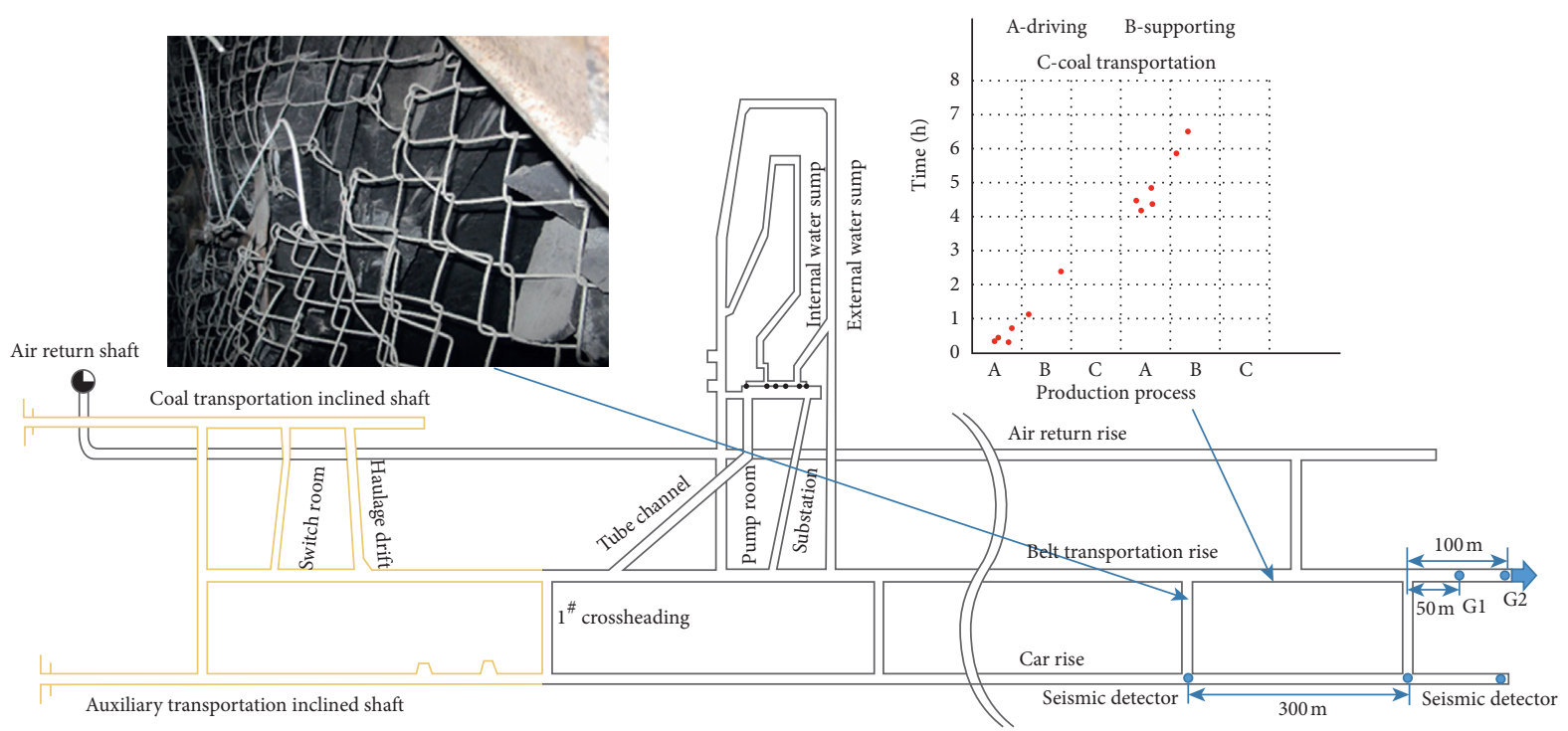

FIGURE 1: Roadway layout plan.

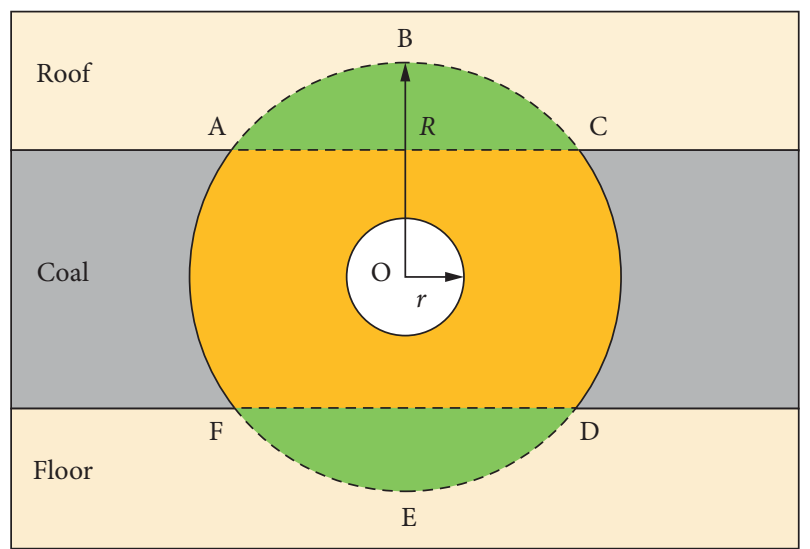

Figure 2: Structural diagram of the roadway surrounding rock.

storage area $\left(\mathrm{m}^{2}\right)$; and $\omega_{c}$ is the energy density of coal seam in the high-energy storage area $\left(\mathrm{J} / \mathrm{m}^{3}\right)$.

The storage and release of energy in coal and rock mass is related to surrounding rock stress and rock properties. Under certain stress conditions, a certain critical energy is stored in the coal and rock mass. The higher the primary rock stress, the smaller the elastic modulus of the rock and the higher the stored elastic energy. The research by Zhu et al. $[43,44]$ revealed that the energy density ratio of coal seam to rock stratum is $1.8-2.3$, and the elastic energy accumulated in the surrounding rock of the driving face of the extremely thick coal seam is much higher than that of the thin and medium thick coal seams at the same depth. After the roadway is excavated, the stress of the roadway surrounding rock is redistributed. Under the condition that the roadway surrounding rock consists of a certain coal seam, once the accumulated energy exceeds the critical stored energy $\left(E_{0}\right)$ of the coal seam under the new stress state, a part of the energy exceeding the critical stored energy $\left(E_{01}\right)$ results in the fracture damage of the roadway surrounding rock, while the other part $\left(E_{02}\right)$ pushes the broken coal seam outward. The relationship among $E_{0}, E_{01}$, and $E_{02}$ is expressed by equation (2). If the released energy is high enough, it will cause an impact. The weak impact occurring in the excavation process of the extremely thick coal seam in Yili No. 1 Coal Mine is mainly caused by $E_{02}$.

$$
E_{0}=E_{01}+E_{02}
$$

where $E_{0}$ is the energy exceeding the critical energy storage of coal and rock mass; $E_{01}$ is the fracture energy of coal and rock mass; and $E_{02}$ is the impact energy of coal and rock mass.

2.2. Analysis on the Near-Field Microseism of the Driving Face. In order to study the location and energy of the near-field weak impact in the driving face, microseismic monitoring equipment is set up in the driving face [45-49]. The adopted ESG microseismic monitoring system (made in Canada), whose acquisition frequency is $50-10 \mathrm{kHz}$, comprises sensors, a Paladin digital signal acquisition system, an optical cable data communication system, and a Hyperion digital signal processing system.

Monitoring points are arranged at the intersection of the car rise and the connecting roadway. The first monitoring section is arranged at the intersection of the $6^{\#}$ crossheading (Figure 1) and the car rise. With the excavation along the three car rises, another monitoring section is arranged at the next intersection with an interval of $300 \mathrm{~m}$. In this way, the monitoring sections are continuously arranged to ensure the continuity and accuracy of microseism signals during roadway excavation. A seismic detector is arranged at the roadway roof, sides, and floor in each monitoring section, respectively.

Figure 3 shows the spatial distribution of seismic events in the near-field area of the driving face. The seismic events occurring at different positions in 10 driving classes are counted, and the driving face advances for $2.4 \mathrm{~m}$ in each driving class. The coordinates are arranged on the driving 


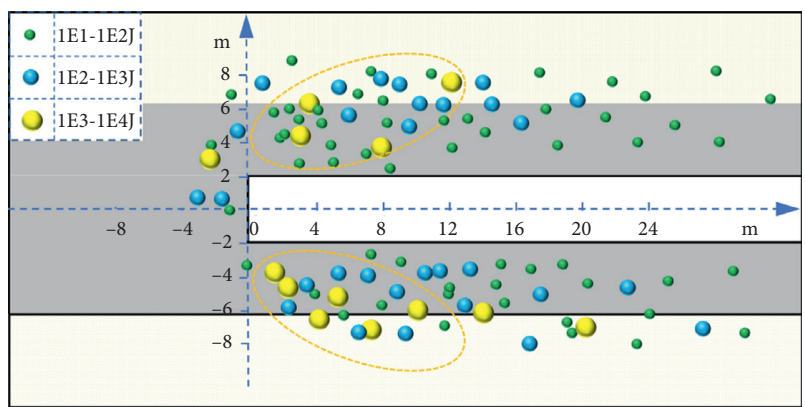

FIGURE 3: Spatial distribution of near-field seismic events in the driving face.

face, and they move with the advancement of the driving face. The spheres in the figure represent seismic events, and their different colors and sizes represent different energy ranges.

As can be seen from Figure 3, in the area $0-8 \mathrm{~m}$ behind the driving face, seismic events are densely distributed in the range of 2-6 $\mathrm{m}$ in the roof and the floor, modestly distributed within $2 \mathrm{~m}$ in the roof and the floor, and sparsely distributed beyond $6 \mathrm{~m}$ in the roof and the floor. Since this area is located in the vicinity of the roadway surface, the coal here is rapidly destroyed under the action of concentrated stress, and there exist a large number of cracks. Therefore, the seismic events here are small and of low energy. The area 8-14 m behind the driving face is a medium-density seismic event area, and the area beyond $14 \mathrm{~m}$ behind the driving face is a low-density seismic event area. Because energy in coal and rock mass has been released, seismic events in these two areas are significantly reduced. In addition, the numbers of seismic events and high-energy events in the floor are both greater than those in the roof. The main reason is that the floor is not supported, so it becomes the breakthrough of energy release.

\subsection{Analysis on the Near-Field Fracture Damage Evolution of} the Driving Face. In order to study the fracture evolution process of the roadway surrounding rock in the extremely thick coal seam, two observation boreholes are set up at the driving face roof and sides on the car rise (buried depth: $680 \mathrm{~m}$ ). The observation results at the roof are analyzed in this section. After the observation boreholes are arranged, the observation is conducted for every other driving class. The observation results are shown in Figure 4. With the advance of the driving face, the fracture damage of the roadway surrounding rock develops quickly to the deep. It is observed that the roadway surrounding rock is broken, with obvious ring fractures and radial fractures. The third observation ( $14.4 \mathrm{~m}$ away from the driving face) discloses that the fracture range of the roadway surrounding rock is $1.3 \mathrm{~m}$. In the fourth observation $(19.2 \mathrm{~m}$ away from the driving face) and the fifth observation ( $24 \mathrm{~m}$ away from the driving face), no obvious new cracks are found anywhere else except positions $2.9 \mathrm{~m}$ and $3.2 \mathrm{~m}$ away from the borehole, indicating that weak impact gradually ceases causing fracture damage when the roadway is about $20 \mathrm{~m}$ away from the driving face. Moreover, the loose circle of the roadway surrounding rock in the extremely thick coal seam is large and develops rapidly for two reasons: first, the $E_{02}$ weak impact induced fracturing of the roadway surrounding rock; second, the concentrated stress of the surrounding rock causes plastic failure.

\section{Study on "Pressure Relief" of the Weak Impact Roadway in the Extremely Thick Coal Seam}

If the impact energy $E_{02}$ is reduced, its damage to the roadway can be weakened, which can be realized by taking effective pressure relief measures to lower the stress concentration degree of the roadway surrounding rock. In this paper, two pressure relief plans are proposed: large-diameter boreholes and stepped driving. To comparatively study their pressure relief effects, the numerical simulation method is adopted for analysis.

\subsection{Calculation Model and Mechanical Parameters}

3.1.1. Numerical Model. The cross section of the transportation rise near the $6^{\#}$ crossheading is taken as the numerical model. The parameters are as follows: buried depth $700 \mathrm{~m}$, roadway net width $6.0 \mathrm{~m}$, roadway net height $5.0 \mathrm{~m}$, arch height $3.0 \mathrm{~m}$, and wall height $2 \mathrm{~m}$. Considering the location and cross-sectional shape of the roadway, as well as the needs of research, the size of the model is $60 \mathrm{~m} \times 50 \mathrm{~m} \times 30 \mathrm{~m}$. The model basically restores the current state of roadway excavation with respect to geological conditions, physical and mechanical properties, cross-section design parameters, etc. The model size and boundary conditions are shown in Figure 5. It has 276,507 units and 49,021 nodes.

3.1.2. Main Mechanical Parameters. The calculation is conducted based on the elastic-plastic model, and the Mohr-Coulomb yield criterion is used to judge the failure of coal and rock mass.

$$
f_{s}=\sigma_{1}-\sigma_{3} \frac{1+\sin \phi}{1-\sin \phi}-2 c \sqrt{\frac{1+\sin \phi}{1-\sin \phi}}
$$

where $\sigma_{1}$ and $\sigma_{3}$ are the maximum and minimum principal stresses, respectively; $c$ is the cohesion; and $\varphi$ is the internal friction angle. When $f_{s}>0$, coal and rock mass will undergo shear failure. In the normal stress state, the tensile strength $\sigma_{T}$ of coal and rock mass is very low, so whether the coal and rock mass undergo tensile failure can be judged according to the tensile strength criterion $\left(\sigma_{3} \geq \sigma_{T}\right)$.

The parameters of simulation calculation are determined in accordance with the mechanical parameters obtained from field sampling and mechanical testing, as listed in Table 1.

\subsection{Numerical Simulation Analysis on Roadway Pressure Relief in the Extremely Thick Coal Seam}

3.2.1. Analysis on Pressure Relief by Circular Advancing Boreholes. In order to relieve the pressure in the advancing direction during roadway excavation, eight $30 \mathrm{~mm}$-long 

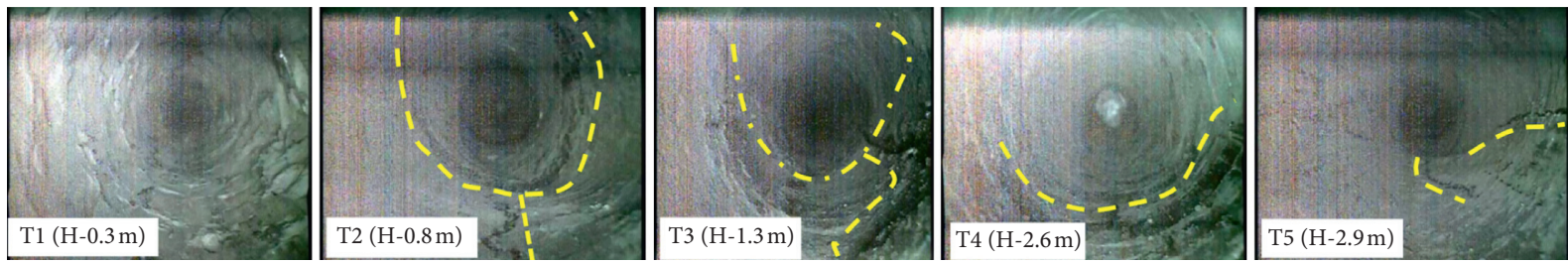

FIGURE 4: Observation results of the roadway surrounding rock fracture in the extremely thick coal seam.

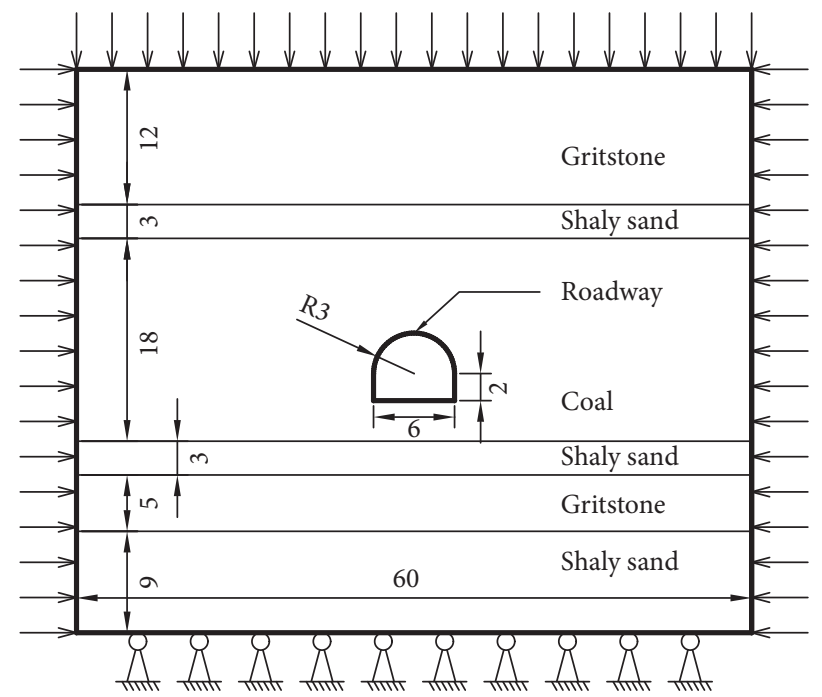

FIgURe 5: Model size and boundary conditions.

TABLE 1: Numerical calculation of mechanical parameters of the coal and rock.

\begin{tabular}{|c|c|c|c|c|c|c|c|}
\hline Coal and rock & $\begin{array}{c}\text { Tensile strength } \\
(\mathrm{MPa})\end{array}$ & $\begin{array}{c}\text { Compressive strength } \\
(\mathrm{MPa})\end{array}$ & $\begin{array}{c}\text { Elastic modulus } \\
(\mathrm{MPa})\end{array}$ & $\begin{array}{l}\text { Poisson's } \\
\text { ratio }\end{array}$ & $\begin{array}{c}\text { Internal friction } \\
\text { angle }\end{array}$ & $\begin{array}{c}\text { Cohesion } \\
(\mathrm{MPa})\end{array}$ & $\begin{array}{l}\text { Density } \\
\left(\mathrm{kg} / \mathrm{m}^{3}\right)\end{array}$ \\
\hline Coarse sandstone & 0.69 & 9.61 & $1,991.5$ & 0.235 & 46.3 & 2.72 & 2,397 \\
\hline $\begin{array}{l}\text { Argillaceous } \\
\text { sandstone }\end{array}$ & 0.77 & 5.43 & 1,026 & 0.241 & 45 & 1.83 & 2,144 \\
\hline No. 3 coal seam & 0.21 & 6.20 & 1,140 & 0.266 & 32 & 1.78 & 1,280 \\
\hline
\end{tabular}

circular boreholes with the diameters of $100 \mathrm{~mm}, 200 \mathrm{~mm}$, and $300 \mathrm{~mm}$ are drilled along the advancing direction, respectively. The layout of the boreholes is exhibited in Figure 6.

As shown in Figures 7-9, no matter which pressure relief scheme is adopted, only small pressure relief areas are formed around the 8 boreholes. Even if the diameter of the boreholes reaches $300 \mathrm{~mm}$, the pressure relief areas of different boreholes are not connected, that is, no large pressure relief area is formed within the roadway section, and no pressure relief effect is achieved in the surrounding rock beyond the roadway section. Consequently, the impact energy $E_{02}$ cannot be reduced.

For the 8 pressure relief boreholes with the diameter of $100 \mathrm{~mm}$, the test results suggest that, during the roadway excavation process, the borehole wall remains intact; the boreholes are basically undamaged; and the impact strength of the roadway surrounding rock is not notably reduced.
3.2.2. Analysis on Pressure Relief by Stepped Driving. Aiming at comparatively analyzing the feasibility of driving construction, two driving schemes, namely, nonstepped driving and stepped driving, are adopted in this paper. In the stepped driving scheme, three steps with the heights of $1.5 \mathrm{~m}$, $1.5 \mathrm{~m}$, and $2.0 \mathrm{~m}$ are arranged positively from top to bottom, respectively, and the driving footage is $5 \mathrm{~m}$.

The nonstepped and stepped driving pressure relief schemes are compared in Figures 10-12. It can be observed that their stress distributions and plastic zone ranges do not differ much after the surrounding rock roadway stabilizes. However, in the stepped driving scheme, the stress concentration in front of the roadway is completely eliminated, and those on both sides are also significantly reduced due to the sufficient movement space and the relatively small driving section. The advancing driving steps in this scheme can efficiently relieve the pressure in the roadway surrounding rock, thus decreasing the impact energy $E_{02}$ in 


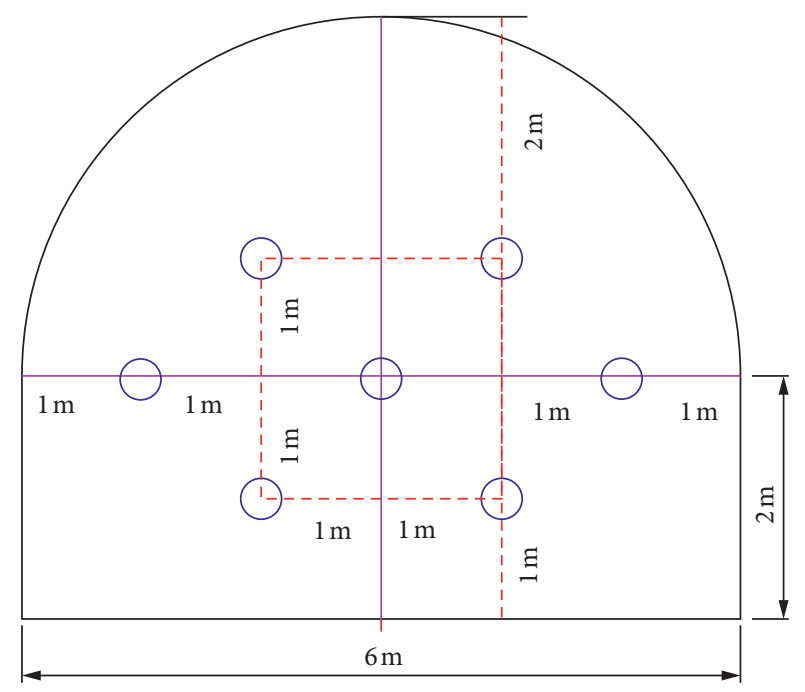

FIGURE 6: Layout of pressure relief boreholes.

advance. Field practice shows that both numbers of seismic events and high-energy events in the roadway surrounding rock are greatly reduced after the application of stepped driving, but the occurrence of weak impact cannot be completely eliminated.

\section{Study on the "Yielding Pressure" Support Technology of the Weak Impact Roadway in the Extremely Thick Coal Seam}

4.1. Working Load Variations of Roadway Bolts in the Extremely Thick Coal Seam. Although the pressure relief can reduce part of the impact energy $E_{02}$, it fails to completely eliminate the weak impact. The deformation of the roadway surrounding rock under the weak impact in the extremely thick coal seam mainly includes two parts. One is fracturing and deformation caused by weak impact, and the other is plastic failure caused by concentrated stress. These two parts of deformation jointly induce considerable deformation of the roadway surrounding rock. As a result, the working load of bolts is increased, even exceeding the strength limit of bolts.

The cross section $50 \mathrm{~m}$ away from the $7^{\#}$ crossheading (point G1 in Figure 1) on the transportation rise in Yili No. 1 Coal Mine is supported by means of MSGLD-500/22 bolts, meshes, anchor cables, and shotcrete. After the excavation of the driving face is completed, the roadway surrounding rock deforms quickly and severely, which puts a huge load on the bolt supporting structure. Resultantly, bolts and anchor cables break frequently. Figure 13 displays the change curves of the working loads of the roof anchor (the $7^{\#}$ anchor) and the left anchor (the $10^{\#}$ anchor). After 15 days of work, the working load of the $7^{\#}$ anchor has reached $250 \mathrm{kN}$, and the rod has broken. After 16 days of work, the working load of the $10^{\#}$ bolt has reached $220 \mathrm{kN}$, far exceeding the initial yielding load. The results indicate that the currently used bolts are not suitable for the roadway surrounding rock that has severely deformed under the weak impact in the extremely thick coal seam.
4.2. Test Analysis on the Elongation Percentage of Ordinary Bolts. Three $500 \mathrm{~mm}$-long MSGLD-500/22 bolts produced by different manufacturers are selected for conducting tensile tests, so as to analyze their deformation characteristics. The test results are shown in Figure 14. The average elongation percentages of the elastic segment, the yielding segment, and the strengthening deformation segment are $2.44 \%, 1.50 \%$, and $11.13 \%$, respectively, and that within the bolt strength limit is $15.07 \%$. Considering the necking characteristics of the bolt rod, for steel whose yielding strength is over $500 \mathrm{MPa}$, the elongation percentage of the bolt rod takes $8 \%$ in the design of roadway support. At present, MSGLD-500/22 usually adopts the partial anchorage. If the anchorage length is $1,000 \mathrm{~mm}$, the free section length of a $2,400 \mathrm{~mm}$-long bolt is $1,400 \mathrm{~mm}$. Calculated according to the elongation rate of $8 \%$, the deformation length is $112 \mathrm{~mm}$ which is not enough to bear the deformation of the coal roadway surrounding rock within the anchoring range under vibration conditions. Consequently, part of the anchor rod breaks. Hence, the elongation percentage must be increased before necking or breakage of the bolt rod.

4.3. Test Analysis on the Deformation of Yielding Bolts. When the roadway surrounding rock experiences large deformation, the current elongation percentage of the bolt cannot adapt to the large deformation. When the deformation of the surrounding rock within the anchorage range is greater than the elongation that the bolt can bear, the bolt will break and lose the support function. Even worse, accidents such as roof fall and collapse may occur. In Yili No. 1 Coal Mine, the impact energy of the three rises is relatively small. Although some bolts are broken due to the large deformation of the roadway, statistics show that the percentage of broken bolts is about $20 \%$. Therefore, it is considered to apply double-bubble yielding bolts to the three rises.

A yielding bolt mainly boasts two functions in the weak impact roadway: first, it can promote the deformation capacity of the bolt supporting structure. When the bolt is subjected to a large tensile force, the yielding tube can undertake part of the deformation to prevent the bolt from breaking, thus protecting the bolt supporting system. Second, the anchored rock mass deforms under the condition of near-constant resistance, which can not only reduce the additional pressure brought by the impact-induced harmful deformation to the supporting structure but also release a part of the impact energy of the surrounding rock. In this way, it can better control the development of the broken zone and plastic zone of the surrounding rock, so as to maintain the stability of the roadway. Considering that the yielding tube serves to protect the bolt, the initial yielding strength of the yielding tube should be slightly higher than the initial yielding strength of the bolt.

In order to obtain its compression deformation law, the double-bubble yielding bolt is designed for the MSGLD$500 / 22$ bolt. The calculated yielding strength of the bolt rod is $189 \mathrm{kN}$; the designed length of the yielding bolt is $70 \mathrm{~mm}$; 

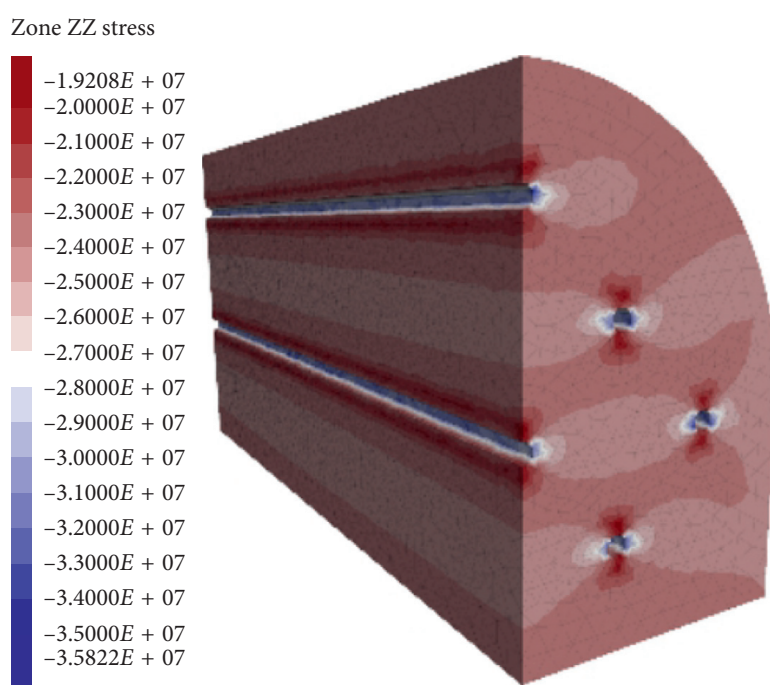

(a)
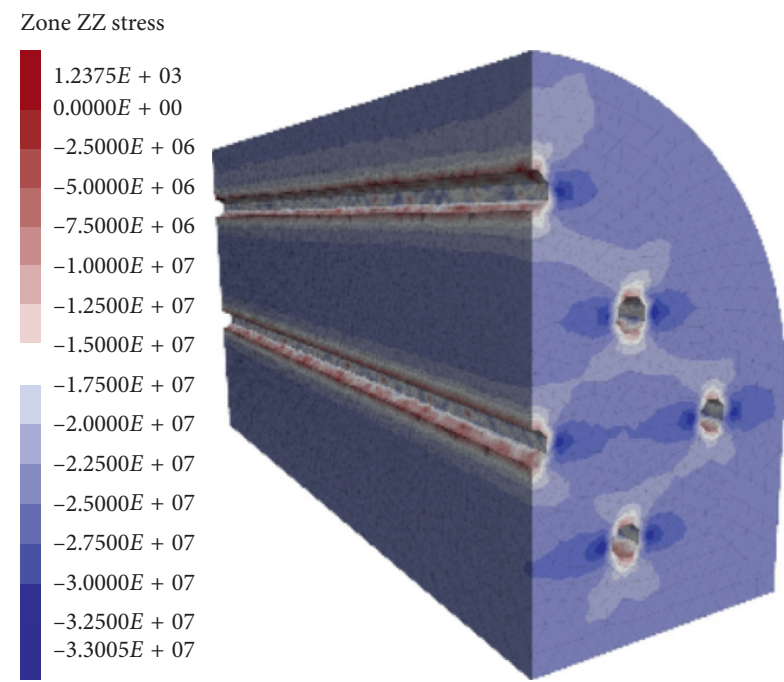

(b)
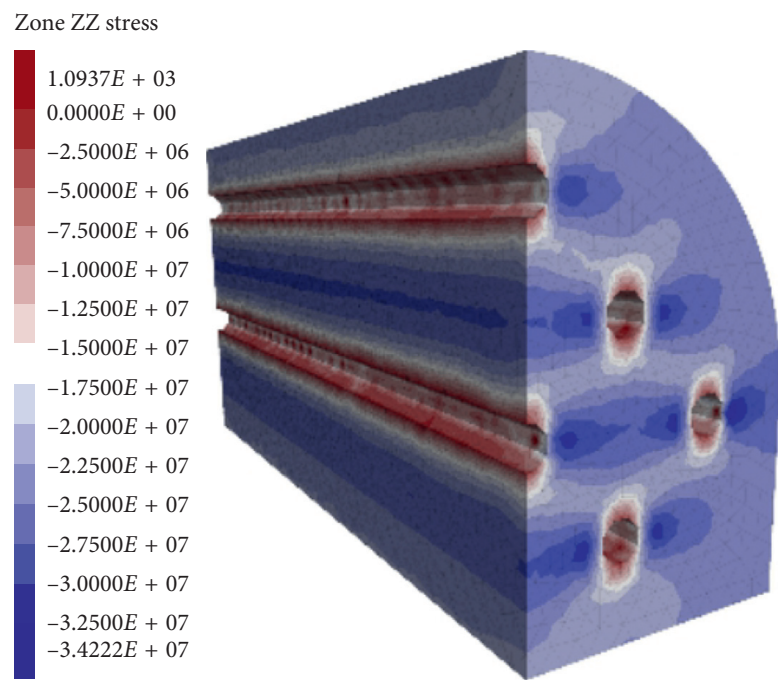

(c)

Figure 7: Vertical stresses of pressure relief boreholes. (a) $\Phi 100 \mathrm{~mm}$. (b) $\Phi 200 \mathrm{~mm}$. (c) $\Phi 300 \mathrm{~mm}$.

and the initial yielding strength of the yielding bolt is designed to be 1.1 times the calculated yielding strength of the bolt rod, namely, $210 \mathrm{kN}$. The yielding bolt is installed on the $500 \mathrm{~mm}$-long MSGLD-500/22 rod body first, and then the tensile test is carried out on the ZCMG-600D digital display mining bolt (anchor cable) tension testing machine. Figure 15 displays the test curve which can be divided into five sections. First, the yielding tube and the bolt rod undergo elastic deformation (displacement $12 \mathrm{~mm}$, section A). Next, the yielding bolt yields at $207 \mathrm{kN}$ (displacement $14.5 \mathrm{~mm}$, section B). Afterwards, bubble 1 starts to deform and yield (displacement $26 \mathrm{~mm}$, section $\mathrm{C}$ ). Then, bubble 2 deforms and yields (displacement $22.5 \mathrm{~mm}$, section D). Finally, the bolt rod is broken (section F).

Through the above analysis, it is known that deformation yielding sections $\mathrm{C}$ and $\mathrm{D}$ are the main deformation sections of the yielding tube. The deformation yielding length of the yielding tube is $48.5 \mathrm{~mm}$ in the test. In practice, if the yielding distance of a double-bubble yielding tube is not enough, one or two double-bubble yielding tubes can be added in the yielding bolt to meet the requirements of the field engineering.

\section{Engineering Practice Verification}

The above analysis suggests that stepped driving for extremely thick coal seam roadways can decrease the magnitude of impact and the number of seismic events. Therefore, this mining method is applied on the transportation rise $100 \mathrm{~m}$ away from the $7^{\#}$ crossheading (point G2 in Figure 1) in Yili No. 1 Coal Mine. In consideration of the convenience of construction, the driving proceeds in the two (upper and lower) steps divided by the arch base line. Furthermore, a double-bubble yielding tube is installed on the pressure relief bolt so that the bolt can improve the deformability of the supporting structure and prevent the bolt from breaking under large deformation conditions. 

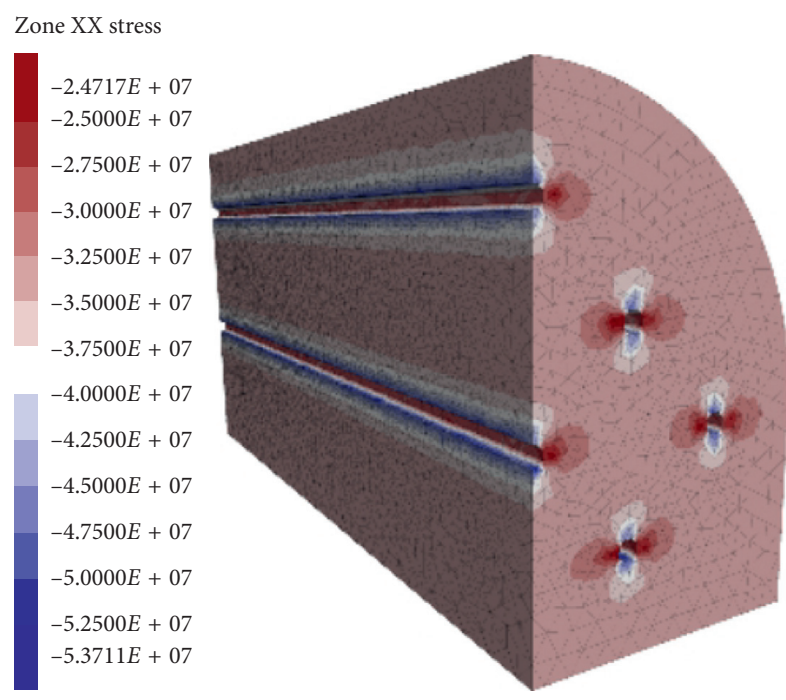

(a)

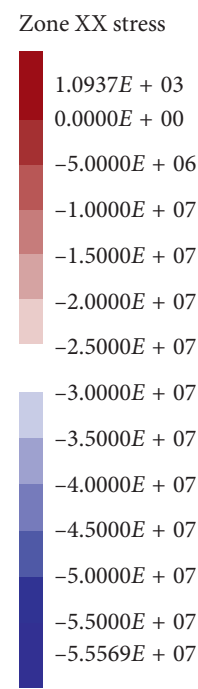

Zone XX stress
$1.2375 E+03$
$-2.5000 E+06$
$-7.5000 E+06$
$-1.2500 E+07$
$-1.7500 E+07$
$-2.2500 E+07$
$-2.7500 E+07$
$-3.2500 E+07$
$-3.7500 E+07$
$-4.2500 E+07$
$-4.7500 E+07$
$-4.9468 E+07$

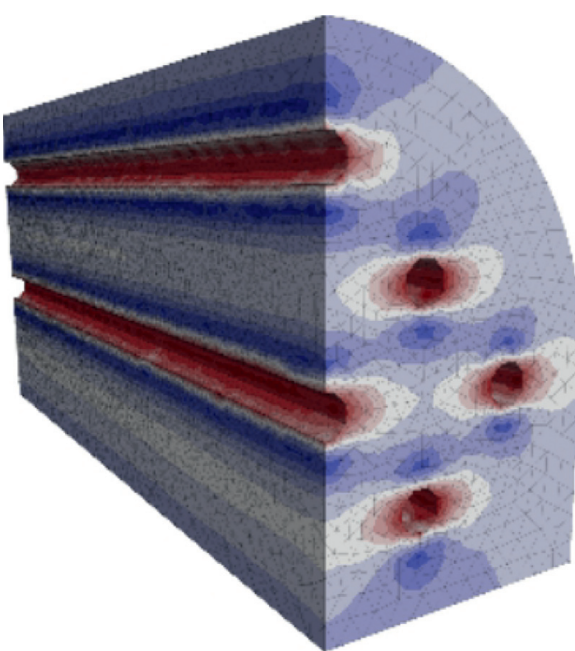

(b)

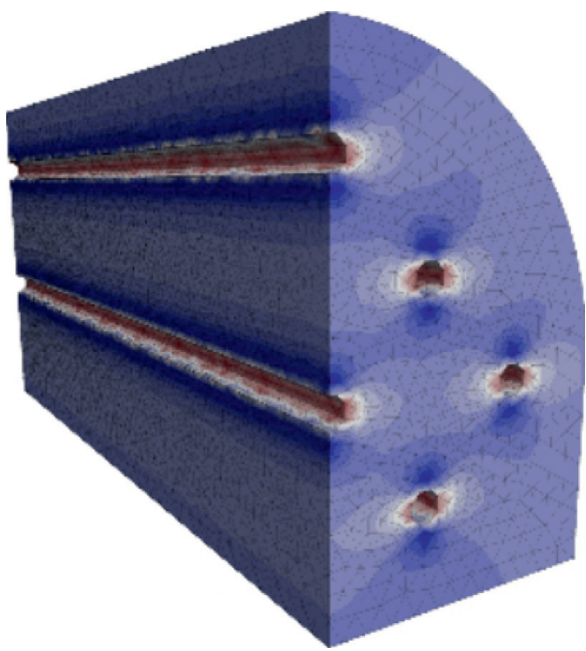

(c)

Figure 8: Horizontal stresses of pressure relief boreholes. (a) $\Phi 100 \mathrm{~mm}$. (b) $\Phi 200 \mathrm{~mm}$. (c) $Ф 300 \mathrm{~mm}$.

5.1. Support Design. The transportation rise in Yili No. 1 Coal Mine is supported by means of bolts, meshes, anchor cables, and shotcrete [50-54]. The roadway support section is presented in Figure 16. The specific support parameters are as follows: MSGLD-500/22 × 2400 bolt, "Wuhua" layout, interrow spacing $800 \mathrm{~mm} \times 800 \mathrm{~mm}$, anchorage length $\geq 1,400 \mathrm{~mm}$, pull-out force $\geq 200 \mathrm{kN}$, and pretension force $\geq 50 \mathrm{kN}$. The $\Phi 22 \mathrm{~mm} \times 8,300 \mathrm{~mm}$ anchor cables of $1 \times 19$ structure are arranged from the top to both sides with the spacing of $2,200 \mathrm{~mm}$. The anchor cables at two shoulder sockets are used to replace two bolts arranged in the "Wuhua" layout, with the spacing of 2,200 $\mathrm{mm} \times 2,400 \mathrm{~mm}$. The pull-out force is $400 \mathrm{kN}$, and the pretension force is over $200 \mathrm{kN}$. One $70 \mathrm{~mm}$-long double-bubble yielding tube whose yielding value and yielding distance are $210 \mathrm{kN}$ and $48.5 \mathrm{~mm}$, respectively, is added in each bolt, and two $150 \mathrm{~mm}$-long double-bubble yielding tubes whose yielding value and yielding distance are $350 \mathrm{kN}$ and $100 \mathrm{~mm}$, respectively, are added in each anchor cable. Four tubes of K2835 resin cartridges are used for each bolt, and six tubes of K2835 resin cartridges are used for each anchor cable. Archshaped high-strength pallets are selected, the sizes being $150 \mathrm{~mm} \times 150 \mathrm{~mm} \times 10 \mathrm{~mm}$ for the bolt and $300 \mathrm{~mm} \times 300 \mathrm{~mm} \times 16 \mathrm{~mm}$ for the anchor cable. The $\Phi 8 \mathrm{~mm}$ steel mesh is selected, the size being $80 \mathrm{~mm} \times 80 \mathrm{~mm}$. The shotcrete thickness and strength are $100 \mathrm{~mm}$ and C20, respectively.

\subsection{Monitoring of Roadway Stability under "Pressure Relief and Yielding Support" Joint Prevention and Control}

5.2.1. Microseismic Monitoring. After adopting the "pressure relief and yielding support" joint prevention and control technology, microseismic monitoring is carried out on the transportation rise $\left(100 \mathrm{~m}\right.$ away from the $7^{\#}$ 


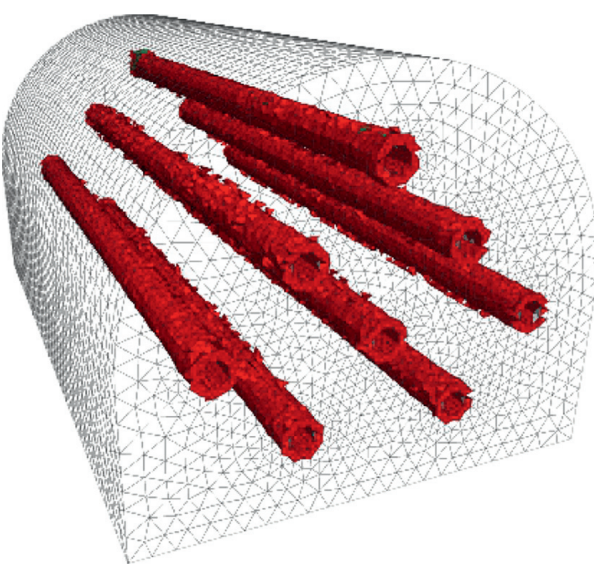

(a)

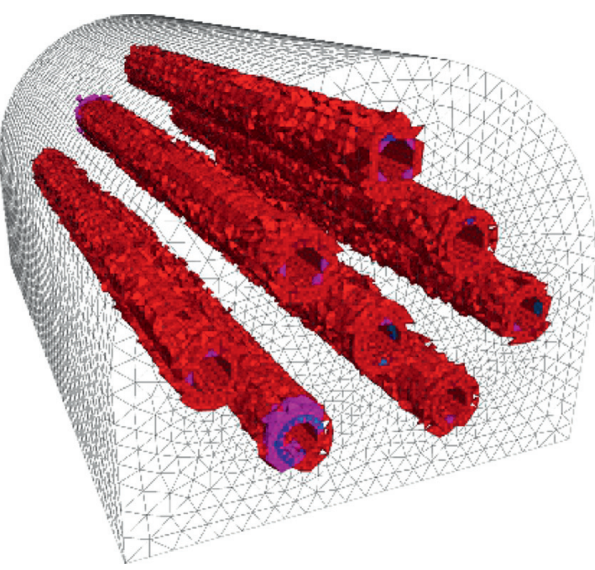

(b)

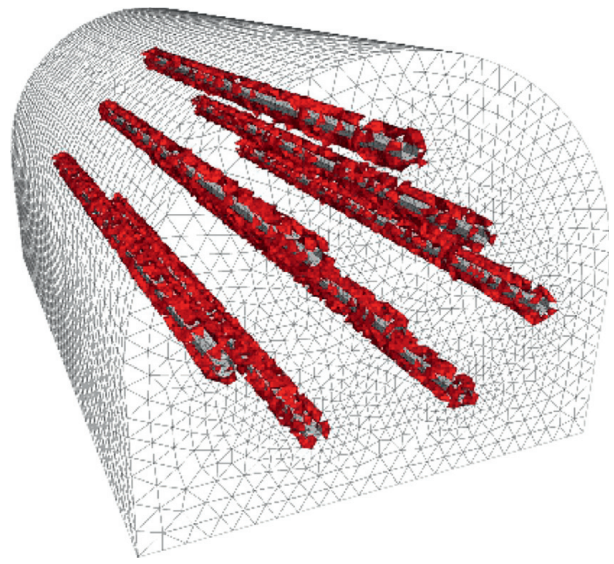

(c)

Figure 9: Plastic zones of pressure relief boreholes. (a) $\Phi 100 \mathrm{~mm}$. (b) $\Phi 200 \mathrm{~mm}$. (c) $\Phi 300 \mathrm{~mm}$.

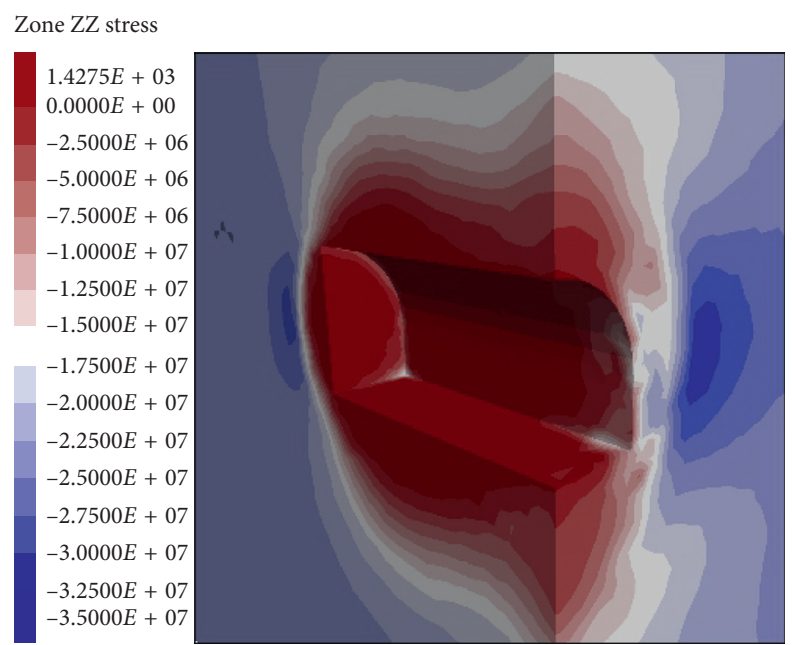

(a)

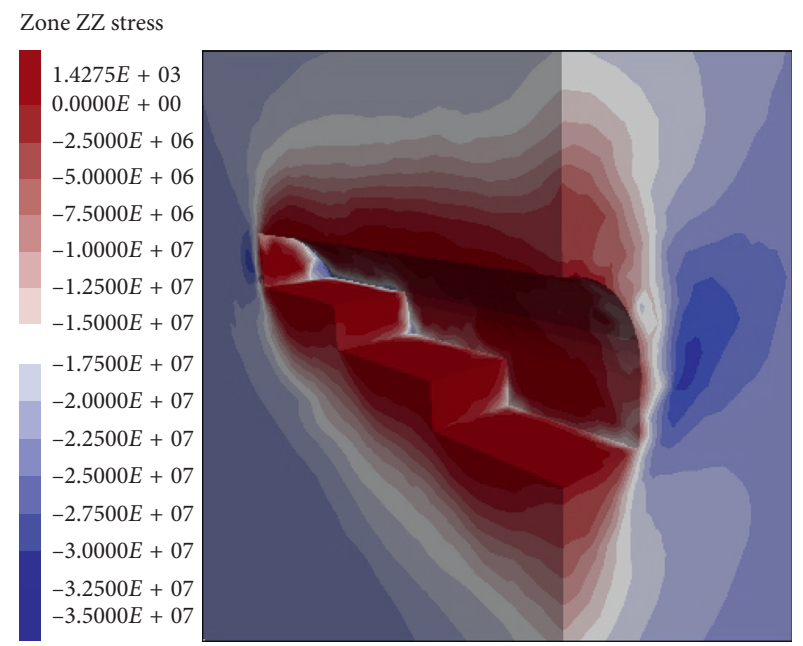

(b)

Figure 10: Vertical stress of stepped driving. (a) Nonstepped driving. (b) Stepped driving. 


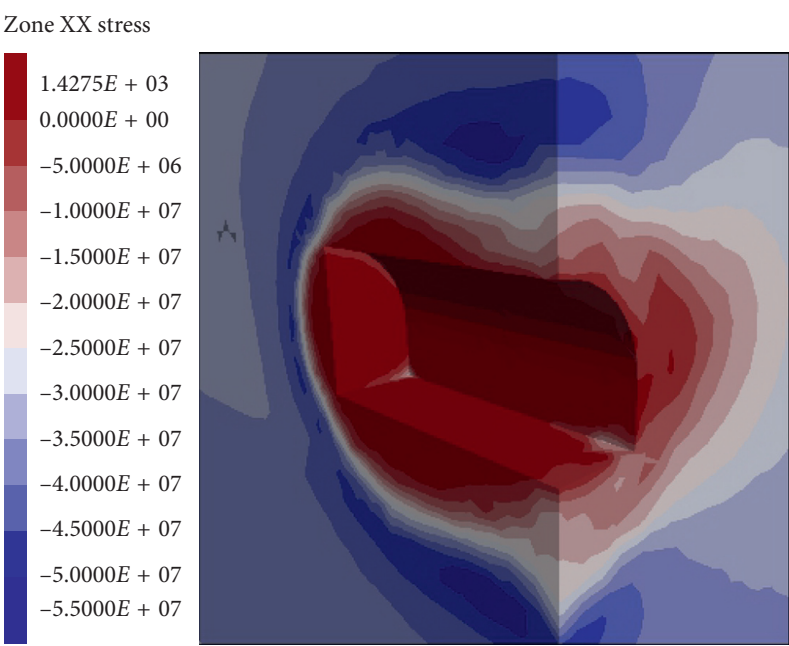

(a)

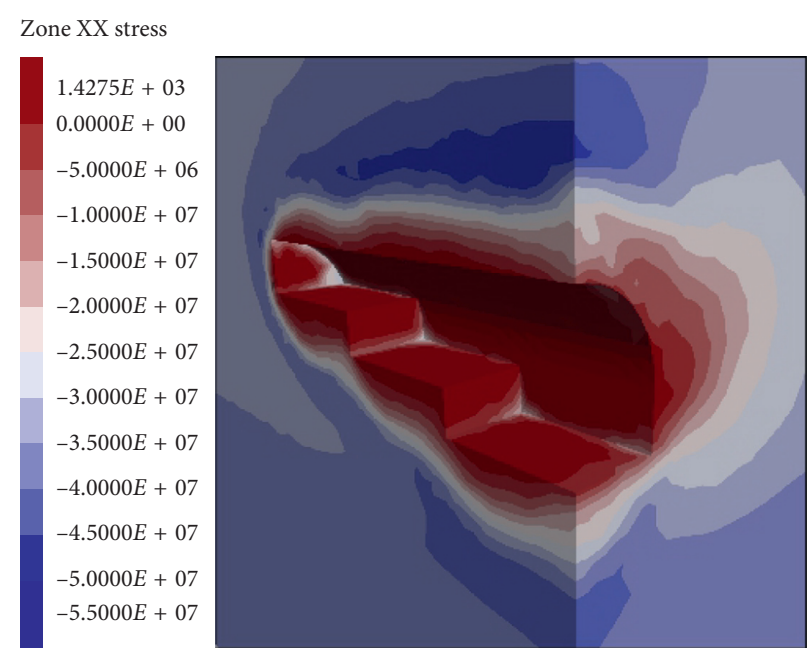

(b)

FIGURE 11: Horizontal stress of stepped driving. (a) Nonstepped driving. (b) Stepped driving.
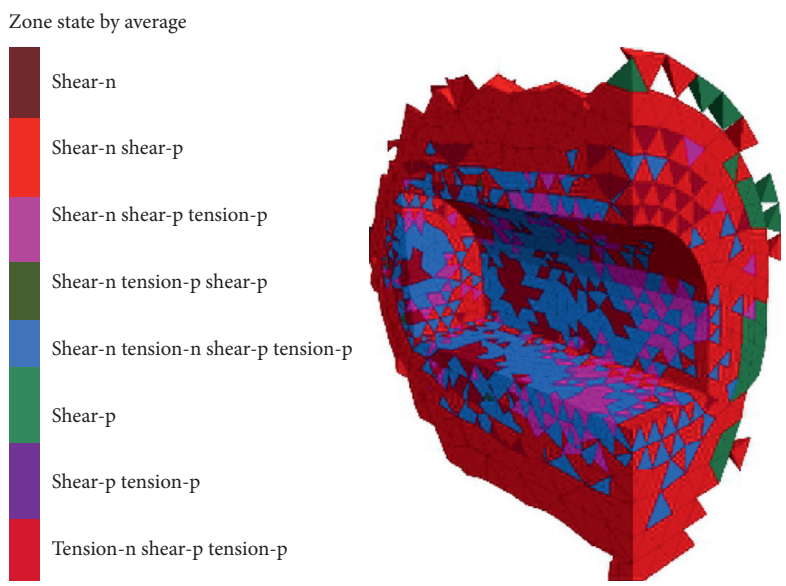

(a)
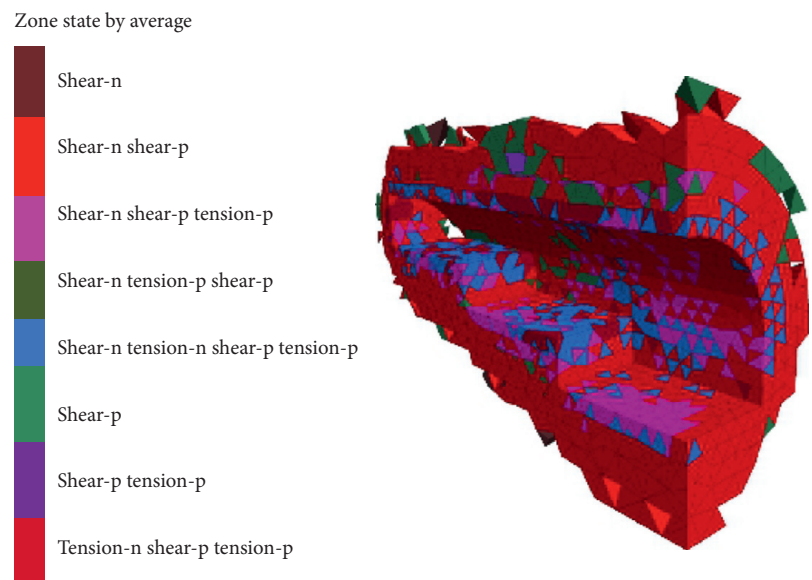

(b)

Figure 12: Plastic zone of stepped driving. (a) Nonstepped driving. (b) Stepped driving.

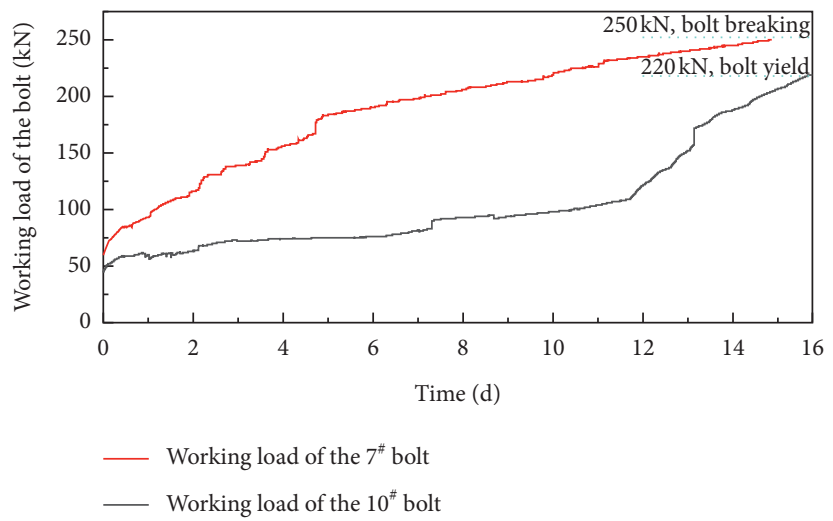

FIGURE 13: Working load variations of roadway bolts in the extremely thick coal seam under the weak impact. 


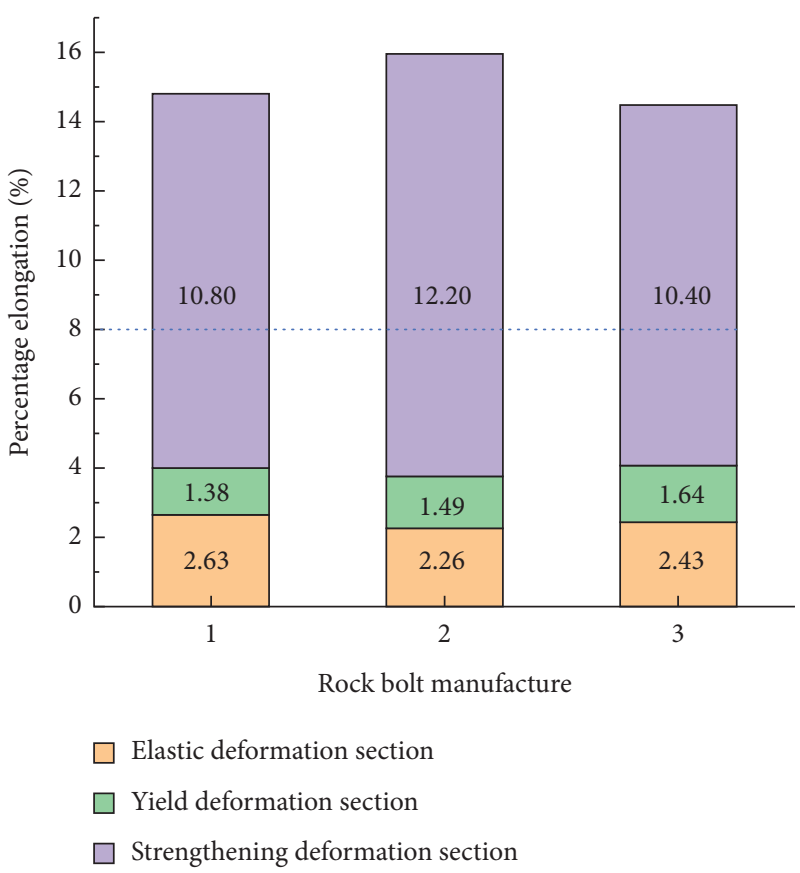

FIGURE 14: Tensile test of MSGLD-500/22 bolts produced by different manufacturers.

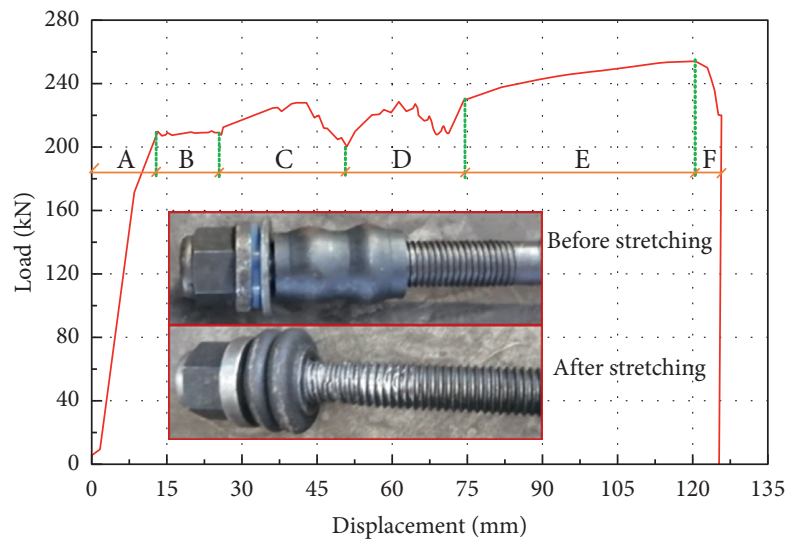

Figure 15: Tensile test curve of the double-bubble yielding bolt. A: elastic deformation section of the yielding bolt; B: yielding section of the bolt rod; C: deformation yield section of bubble 1; D: deformation yield section of bubble 2; E: reinforcement deformation section of the bolt rod; F: fracture section of the bolt rod.

crossheading) of Yili No. 1 Coal Mine. The spatial distribution of near-field microseismic events in the driving face after the application of the technology is illustrated in Figure 17. The results of microseismic monitoring show that the numbers of seismic events and high-energy events in the roof and the floor are remarkably reduced by about $40 \%$. The large-scale decrease of high-energy events and the reduction of microseismic events weaken the damage of the impact load on the roadway surrounding rock.

\subsubsection{Deformation Monitoring of the Roadway Surrounding} Rock. The fracturing of the roadway surrounding rock in the extremely thick coal seam at different depths is analyzed by setting a multipoint extensometer $M$ in the middle of the crown of the transportation rise. The deepest point of the multipoint extensometer is set $10 \mathrm{~m}$ away from the orifice. This point is used as a datum point and is assumed to be fixed. The measuring points are designed to be $0 \mathrm{~m}, 1 \mathrm{~m}, 3 \mathrm{~m}$, $5 \mathrm{~m}$, and $10 \mathrm{~m}$ away from the roadway surface, respectively. The bolt here is lengthened and anchored, with the anchorage length and free section length being $1.4 \mathrm{~m}$ and $1.0 \mathrm{~m}$, respectively. The displacement-time variation curves of the measuring points are exhibited in Figure 18. As can be seen from the figure, the measuring points share basically consistent deformation trends, and the deformation amount gradually decreases from the surface to the inside, the largest displacement occurring at the surface point. The free section of the bolt here refers to the section between the $0 \mathrm{~mm}$-deep measuring point and the $1 \mathrm{~mm}$-deep measuring point. In 


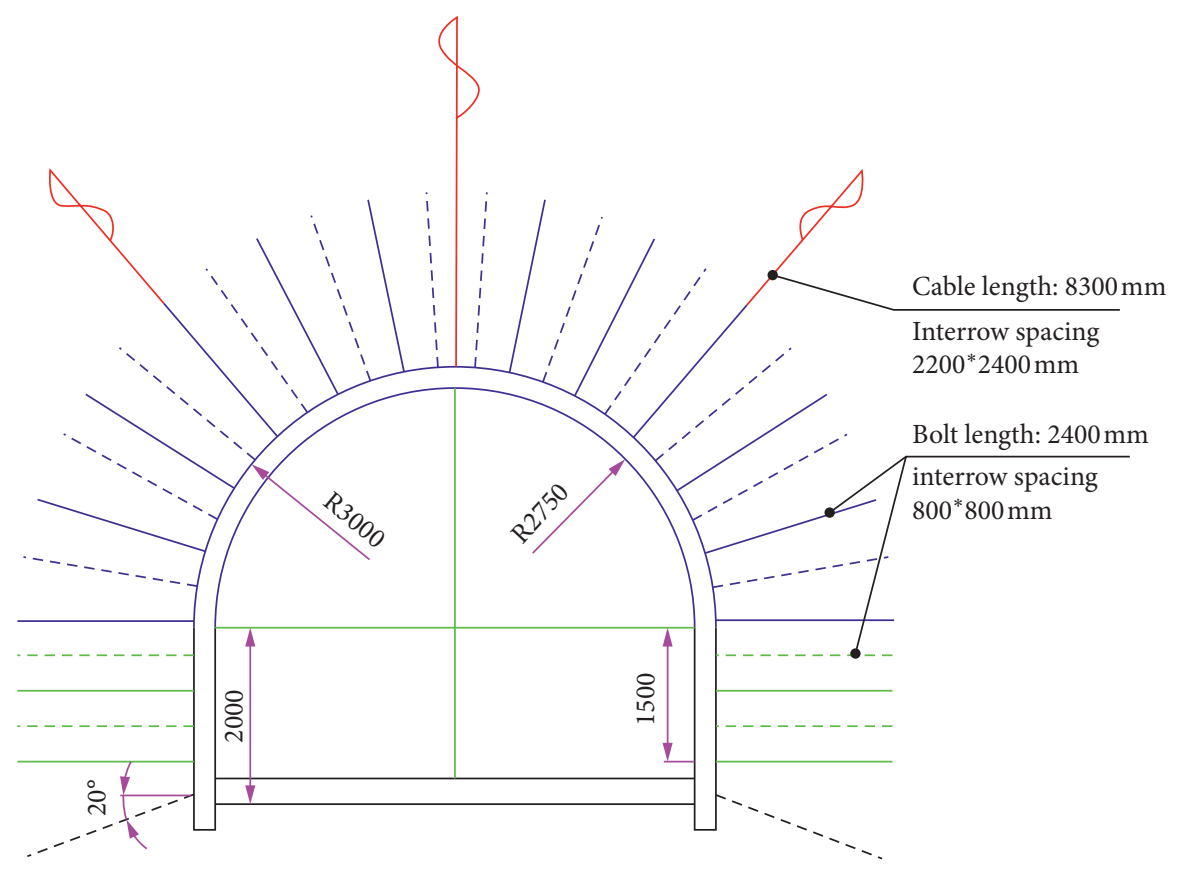

FIGURE 16: Bolt (anchor cable) layout in the roadway section.

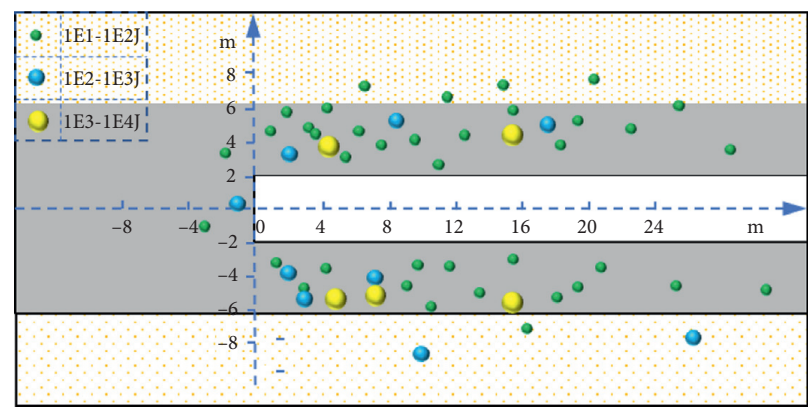

Figure 17: Spatial distribution of near-field microseismic events in the driving face after the application of "pressure relief and yielding support" joint prevention and control technology.

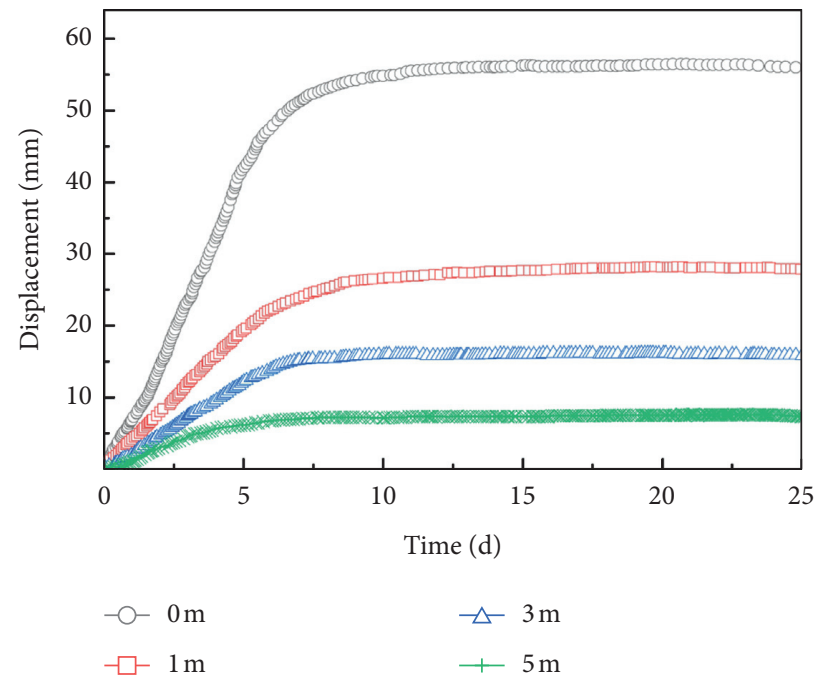

Figure 18: Displacement-time variation curves obtained by using the multipoint extensometer $M$. 


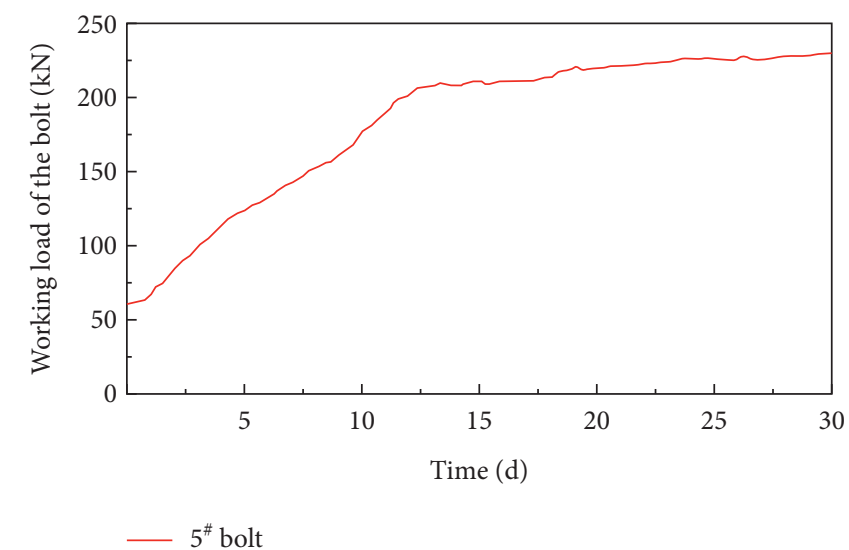

Figure 19: Working resistance-time variation curve of the $5^{\#}$ bolt.

this section, the deformation of the bolt reaches $29 \mathrm{~mm}$, which exceeds the elastic deformation stage of the bolt and enters the yielding stage of the bolt and the yielding tube. Besides, the deformation of the roadway surrounding rock primarily occurs within 15 days after the support, while it gradually stabilizes after 15 days.

5.2.3. Working Resistance Monitoring of the Bolt. The working resistance of the bolt at the crown of the transportation rise is observed with the aid of a bolt dynamometer. The working resistance-time variation curve of the $5^{\#}$ bolt is given in Figure 19. In the first 15 days, the working resistance jumps dramatically by $15 \mathrm{kN} / \mathrm{d}$ on average, which is basically consistent with the monitored surrounding rock deformation trend. In addition, the working resistance on the 15 day reaches $215 \mathrm{kN}$, which has exceeded the elastic limit of the MSGLD-500/22 $\times 2400$ bolt and has entered the yielding stage of the bolt and the yielding tube. After 15 days, the increase in the working resistance drops notably. On the 30th day, the working resistance is $229 \mathrm{kN}$, failing to reach the strength limit of the bolt and remaining in the normal working stage of the bolt. The working resistance monitoring results also demonstrate that the deformation of the roadway surrounding rock tends to become stable after 15 days.

\section{Conclusions}

(1) In this paper, the roadway surrounding rock structure of the extremely thick coal seam is analyzed, and the elastic energy analysis formula under the structure is established. Based on the analysis, it is concluded that the weak impact of the roadway in Yili No. 1 Coal Mine is mainly caused by the impact energy $E_{02}$ of coal and rock mass.

(2) According to the magnitude of microseismic energy and the number of events, the near field of the driving face in the extremely thick coal seam is divided into several areas: in the area $0-8 \mathrm{~m}$ behind the driving face, seismic events are densely distributed in the range of $2-6 \mathrm{~m}$ in the roof and the floor, modestly distributed within $2 \mathrm{~m}$ in the roof and the floor, and sparsely distributed beyond $6 \mathrm{~m}$ in the roof and the floor. The area $8-14 \mathrm{~m}$ behind the driving face is a medium-density seismic event area, and the area beyond $14 \mathrm{~m}$ behind the driving face is a low-density seismic event area.

(3) The "pressure relief and yielding support" joint prevention and control technology is proposed. Numerical simulation reveals that pressure relief boreholes with different diameters cannot effectively relieve pressure and basically cannot reduce the impact energy $E_{02}$. In contrast, in the stepped driving scheme, the stress concentration in front of the roadway is completely eliminated, and those on both sides are also significantly reduced due to the sufficient movement space and the relatively small driving section. The advanced driving steps in this scheme can relieve the pressure in the roadway surrounding rock well, thus decreasing the impact energy $E_{02}$ in advance.

(4) The deformation characteristics of the MSGLD$500 / 22$ bolt are studied. It is considered that the deformation elongation of the bolt cannot match the large deformation of the roadway surrounding rock in the extremely thick coal seam. Accordingly, the tensile test is conducted on the doublebubble yielding tube bolt system. The test results suggest that the deformation yield length of the double-bubble yielding tube reaches $48.5 \mathrm{~mm}$. The double-bubble yielding tube succeeds in endowing the bolt supporting system with the ability to bear large deformation, which can meet the large characteristic deformation of the surrounding rock of the roadway in the extra thick coal seam and can effectively control the deformation of the roadway.

(5) The "pressure relief and yielding support" joint prevention and control technology is applied to the supporting and driving engineering of Yili No. 1 Coal Mine. The microseismic monitoring results show that seismic events and high-energy events of the roof and the floor are greatly reduced by about $40 \%$. The displacement monitoring results 
show that the deformation of the free section of the bolt reaches $29 \mathrm{~mm}$, which exceeds the elastic deformation stage of the bolt and enters the yielding stage of the bolt and the yielding tube. The working resistance monitoring results demonstrate that, on the 30 th day, the working resistance of the bolt is $229 \mathrm{kN}$, failing to reach the strength limit of the bolt and remaining in the normal working stage of the bolt. The displacement and working resistance monitoring results both verify that the double-bubble yielding bolt is suitable for the deformed roadway surrounding rock in the extremely thick coal seam.

\section{Data Availability}

All the data used to support the findings of this study are available from the corresponding author upon request.

\section{Conflicts of Interest}

The authors declare that they have no conflicts of interest.

\section{Acknowledgments}

This work was supported by the National Outstanding Youth Science Fund Project of National Natural Science Foundation of China (CN), 51704180, research on bending failure mechanism of reinforced concrete-filled steel tubular support under uneven load, Jinxiao Liu (skd993938@ sdust.edu.cn).

\section{References}

[1] G. Yang, F. Jia, X. Qu, L. Li, Q. Wei, and N. Li, "Comprehensive monitoring and early warning technology for rockburst of tunneling face with thick coal seams," Chinese Journal of Geotechnical Engineering, vol. 41, no. 11, pp. 2071-2077, 2019.

[2] W. He, F. He, D. Chen, and Q. Chen, "Pillar width and surrounding rock control of gob-side roadway with mechanical caved mining in extra-thick coal seams under hardthick main roof," Journal of Mining \& Safety Engineering, vol. 37, no. 2, pp. 349-358, 2020.

[3] Y. Chen, D. Li, F. Jiang et al., "Prevention mechanism of rock burst in backfill mining in extra-thick coal seam with deep shaft," Journal of Mining \& Safety Engineering, vol. 37, no. 5, pp. 969-976, 2020.

[4] J. Guo, W. Wang, S. Yue, F. He, M. Gao, and S. Xie, "Surrounding rock control mechanism and its application of gobside driving entry in extra thick coal seam," Journal of Coal Society, vol. 42, no. 4, pp. 825-832, 2017.

[5] L. Dou, C. Lu, Z. Mou, Y. Qin, and J. Yao, "Intensity weakening theory for rockburst and its application," Journal of Coal Society, vol. 30, no. 6, pp. 690-694, 2005.

[6] J. Pan, Y. Ning, D. Mao, H. Lan, T. Du, and Y. Peng, "Theory of rockburst start-up during coal mining," Chinese Journal of Rock Mechanics and Engineering, vol. 31, no. 3, pp. 586-596, 2012.

[7] M. Gao, Y. He, C. Lu, X. Shao, and Z. Yang, "Coordination mechanism of internal strong active support, soft structure pressure relief and anti-punching of roadway," Journal of Coal Society, vol. 45, no. 8, pp. 2749-2759, 2020.

[8] H. Kang, Y. Wu, J. He, and Y. Fu, "Rock bolting performance and field practice in deep roadway with rock burst," Journal of Coal Society, vol. 40, no. 10, pp. 2225-2233, 2015.

[9] Y. Pan, Q. Qi, A. Wang et al., "Theory and technology of three levels support in bump-prone roadway," Journal of Coal Society, vol. 45, no. 5, pp. 1585-1594, 2020.

[10] A. Wang, Y. Pan, Q. Qi et al., "Strength calculation method of three-level energy absorption support in rockburst roadways for coal mines," Journal of Coal Society, vol. 45, no. 9, pp. 3087-3094, 2020.

[11] Y. Wu, J. Chen, J. Jiao, Y. Zheng, and J. He, "Damage and failure mechanism of anchored surrounding rock with impact loading," Journal of China Coal Society, vol. 43, no. 9, pp. 2389-2397, 2018.

[12] M. Gao, L. Dou, N. Zhang, K. Wang, and B. Zheng, "Strongsoft-strong mechanical model for controlling roadway surrounding rock subjected to rock burst and its application," Rock and Soil Mechanics, vol. 29, no. 2, pp. 359-364, 2008.

[13] Y. Pan, Y. Xiao, Z. Li, and K. Wang, "Study of tunnel support theory of rockburst in coal mine and its application," Journal of Coal Society, vol. 39, no. 2, pp. 222-228, 2014.

[14] J. Liu, Y. Liu, W. Li, X. Zhang, and C. Xin, "Measures to deal roof-shock during tunneling at deep and extra-thick coal," Arabian Journal of Geosciences, vol. 12, no. 6, pp. 1-16, 2019.

[15] B. Zhang and Z. Meng, "Experimental study on floor failure of coal mining above confined water," Arabian Journal of Geosciences, vol. 12, no. 4, 2019.

[16] Y. Li, S. Zhang, and B. Zhang, "Dilatation characteristics of the coals with outburst proneness under cyclic loading conditions and the relevant applications," Geomechanics \& Engineering, vol. 14, no. 5, pp. 459-466, 2018.

[17] X. Sun, B. Shen, and B. Zhang, "Experimental study on propagation behavior of three-dimensional cracks influenced by intermediate principal stress," Geomechanics \& Engineering, vol. 14, no. 25, pp. 195-202, 2018.

[18] J. Cai, J. Liu, and H. Li, "Application of relieving shot in prevention of rockburst," Blasting, vol. 25, no. 1, pp. 1-4, 2008.

[19] B. Lin and S. Zhou, "Outburst preventive mechanism of stress relaxation groove in coal tunnel," Chinese Journal of Geotechnical Engineering, vol. 17, no. 3, pp. 32-38, 1995.

[20] W. Zhu, C. Hou, X. Liu, and M. Zhang, "Numerical simulation on de-stressing with horizontal groove at the two sidewalls around circular underground opening," Chinese Journal of Underground Space and Engineering, vol. 11, no. 6, pp. 1462-1469, 2015.

[21] C. Jia, Y. Jiang, X. Zhang, D. Wang, H. Luan, and C. Wang, "Laboratory and numerical experiments on pressure relief mechanism of large-diameter boreholes," Chinese Journal of Geotechnical Engineering, vol. 39, no. 6, pp. 1115-1122, 2017.

[22] S. Zhu, F. Jiang, X. Shi et al., "Energy dissipation index method for determining rock burst prevention drilling parameters," Rock and Soil Mechanics, vol. 36, no. 8, pp. 2270-2276, 2015.

[23] Y. Qi, H. Jing, B. Meng, Z. Dong, and D. Liu, "Experimental modelling on size effect of pressure relief hole," Journal of Mining \& Safety Engineering, vol. 35, no. 3, pp. 538-544, 2018.

[24] Y. Li, H. Zhang, J. Han, F. Zhu, and C. Guo, "Time effect of borehole pressure relief based on distributed optical fiber sensing technology," Journal of Coal Society, vol. 42, no. 11, pp. 2834-2841, 2017. 
[25] A. Ansell, "Testing and modelling of an energy absorbing rock bolt," Structures Under Shock \& Impact, vol. 6, pp. 417-425, 2000.

[26] C. C. Li and C. Doucet, "Performance of D-bolts under dynamic loading," Rock Mechanics and Rock Engineering, vol. 45, no. 2, pp. 193-204, 2012.

[27] A. Ansell, "Laboratory testing of a new type of energy absorbing rock bolt," Tunnelling and Underground Space Technology, vol. 20, no. 4, pp. 291-300, 2005.

[28] A. Ansell, "Dynamic testing of steel for a new type of energy absorbing rock bolt," Journal of Constructional Steel Research, vol. 62, no. 5, pp. 501-512, 2006.

[29] L. St-Pierre, F. P. Hassani, P. H. Radziszewski, and J. Ouellet, "Development of a dynamic model for a cone bolt," International Journal of Rock Mechanics and Mining Sciences, vol. 46, no. 1, pp. 107-114, 2009.

[30] C. C. Li, "A new energy-absorbing bolt for rock support in high stress rock masses," International Journal of Rock Mechanics \& Mining Sciences, vol. 47, pp. 396-404, 2010.

[31] C. Lian and G. Wang, "Influence of design parameters of prestressed yieldable bolts on stability of deep mine roadway," Chinese Journal of Geotechnical Engineering, vol. 35, no. 2, pp. 452-458, 2013.

[32] B. Zhang, Z. Zhang, B. Wang, and L. Zhou, "Experimental study of application of yielding bolt to large deformation tunnel," Rock and Soil Mechanics, vol. 37, no. 7, pp. 20472055, 2016.

[33] L. Hao, W. Gong, M. He, and Y. Song, "Theoretical model of the double constant-resistance-large -deformation bolts under impact load," Journal of Coal Society, vol. 43, no. S2, pp. 385-392, 2018.

[34] W. Gong, Z. Zhang, X. Gao, M. He, and C. Li, "Investigation on the impact energy for two bolts with constant resistance and large deformation," Chinese Journal of Underground Space and Engineering, vol. 15, no. 1, pp. 116-124, 2019.

[35] X. Sun, D. Wang, C. Wang, X. Liu, B. Zhang, and Z. Liu, "Experimental study of application of yielding bolt to large deformation tunnel," Chinese Journal of Rock Mechanics and Engineering, vol. 33, no. 9, pp. 1765-1771, 2014.

[36] C. Li, M. He, and W. Gong, "Analysis on impact dynamics of negative Poisson's ratio effect of anchor bolt with constant resistance and large deformation," Journal of Coal Society, vol. 41, no. 6, pp. 1393-1399, 2016.

[37] M. He, C. Li, and W. Gong, "Elongation and impacting experimental system for bolts with constant resistance and large deformation and finite element," Chinese Journal of Rock Mechanics and Engineering, vol. 34, no. 11, pp. 2179-2187, 2015.

[38] M. He, J. Wang, X. Sun, and X. Yang, "Mechanics characteristics and applications of prevention and control rock bursts of the negative Poisson's ratio effect anchor," Journal of Coal Society, vol. 39, no. 2, pp. 214-221, 2014.

[39] M. He, C. Li, W. Gong, J. Wang, and Z. Tao, "Support principles of NPR bolts/cables and control techniques of large deformation," Chinese Journal of Rock Mechanics and Engineering, vol. 35, no. 8, pp. 1513-1529, 2016.

[40] M. Gao, G. Zhao, B. Liu, Y. Zhao, and M. Zhang, "Blasting analogical experiment study on the vibration effects of rock burst in coal roadway," Journal of Coal Society, vol. 39, no. 4, pp. 637-643, 2014.

[41] A. Cao, J. Fan, Z. Mou, and X. Guo, "Burst failure effect of mining-induced tremor on roadway surrounding rock," Journal of Coal Society, vol. 35, no. 12, pp. 2006-2010, 2010.
[42] A. Cao, X. Luo, L. Dou, H. Wang, and K. Andrew, "Experimental research on seismic wave transmission and attenuation associated with underground longwall coal mining," Journal of Mining \& Safety Engineering, vol. 28, no. 4, pp. 530-535, 2011.

[43] S. Zhu, F. Jiang, X. Wang, Y. Jiang, T. Ning, and S. Sun, "Energy accumulation characteristics and rockburst mechanism of surrounding rock at heading face of extra-thick coal seam," Chinese Journal of Geotechnical Engineering, vol. 41, no. 11, pp. 2071-2078, 2019.

[44] A. Hua, "Energy analysis of surrounding rocks in underground engineering," Chinese Journal of Rock Mechanics and Engineering, vol. 22, no. 7, pp. 1054-1059, 2003.

[45] F. Jiang, G. Song, L. Kong, and C. Wang, "Research on spread characteristics of micro-seismic wave in mine strata," Chinese Journal of Rock Mechanics and Engineering, vol. 28, no. S1, pp. 2674-2679, 2009, in Chinese.

[46] X. Tian, Z. Li, D. Song et al., "Study on microseismic precursors and early warning methods in a working face experienced frequent rockbursts," Chinese Journal of Rock Mechanics and Engineering, vol. 39, pp. 1-12, 2020.

[47] L. Dou, Y. Jiang, A. Cao et al., "Monitoring and pre-warning of rockburst hazard with technology of stress field and wave field in underground coalmines," Chinese Journal of Rock Mechanics and Engineering, vol. 36, no. 4, pp. 803-811, 2017.

[48] F. Jiang, Y. Yin, Q. Zhu, S. Li, and Z. Yu, "Feature extraction and classification of mining microseismic waveforms via multi-channels analysis," Journal of Coal Society, vol. 39, no. 2, pp. 229-237, 2014.

[49] Q. Zhu, F. Jiang, Z. Yu, Y. Yong, and L. Lyu, "Study on energy distribution characters about blasting vibration and rock fracture microseismic signal," Chinese Journal of Rock Mechanics and Engineering, vol. 31, no. 4, pp. 723-730, 2012.

[50] Z. Zhang, H. Kang, and J. Wang, "Pre-tensioned stress coordination function analysis of bolt-cable anchor support in coal roadway," Journal of Coal Society, vol. 35, no. 6, pp. 881-886, 2010.

[51] Y. Zhang, K. Xie, F. He, Y. Zhuang, and Z. Wang, "Study on supporting rock stability of working face supported by boltmesh-anchor in soft and thick coal seam," Chinese Journal of Rock Mechanics and Engineering, vol. 23, no. 19, pp. 32983304, 2004.

[52] J. Wang, H. Kang, and F. Gao, "Numerical simulation on load-transfer mechanism and stress distribution characteristics of cablebolts," Journal of Coal Society, vol. 33, no. 1, pp. 1-6, 2008.

[53] Q. Meng, L. Han, W. Qiao, J. Zhang, F. Mei, and W. Feng, "Supporting effect and application of bolt-net-anchor coupling support under extremely weak cementation formation," Journal of Mining \& Safety Engineering, vol. 33, no. 5, pp. 770-778, 2016.

[54] J. Zhang, L. Liu, J. Shao, and Q. Li, "Mechanical properties and application of right-hand rolling-thread steel bolt in deep and high stress roadway," Metals, vol. 346, pp. 1-15, 2019. 